Bond University

Research Repository

\title{
A biomechanical analysis of the farmers walk, and comparison with the deadlift and unloaded walk
}

Winwood, Paul; Cronin, John; Brown, Scott; Keogh, Justin

Published in:

International Journal of Sports Science and Coaching

DOI:

10.1260/1747-9541.9.5.1127

Licence:

Other

Link to output in Bond University research repository.

Recommended citation(APA):

Winwood, P., Cronin, J., Brown, S., \& Keogh, J. (2014). A biomechanical analysis of the farmers walk, and comparison with the deadlift and unloaded walk. International Journal of Sports Science and Coaching, 9(5), 1127-1143. https://doi.org/10.1260/1747-9541.9.5.1127

\section{General rights}

Copyright and moral rights for the publications made accessible in the public portal are retained by the authors and/or other copyright owners and it is a condition of accessing publications that users recognise and abide by the legal requirements associated with these rights.

For more information, or if you believe that this document breaches copyright, please contact the Bond University research repository coordinator. 
Title: A BIOMECHANICAL ANALYSIS OF THE FARMERS WALK, AND COMPARISON WITH THE DEADLIFT AND UNLOADED WALK

Paul W. Winwood ${ }^{1,2}$, John B. Cronin ${ }^{1,3}$, Scott R. Brown', and Justin W. L. Keogh ${ }^{1,4,5}$.

${ }^{1}$ Sport Performance Research Institute of New Zealand, School of Sport and Recreation, AUT University, Auckland, New Zealand

${ }^{2}$ Bay of Plenty Polytechnic, School of Applied Science, Tauranga, New Zealand

${ }^{3}$ Edith Cowan University, School of Biomedical and Health Sciences, Perth, Australia

${ }^{4}$ Faculty of Health Sciences and Medicine, Bond University, Gold Coast, Australia

${ }^{5}$ University of the Sunshine Coast, Faculty of Science, Health, Education and Engineering

Queensland, Australia

Paul Winwood, Ph 08002677659 x6125 Email paul.winwood@boppoly.ac.nz 


\begin{abstract}
This study compared the biomechanical characteristics of the farmers walk, deadlift and unloaded walk. Six experienced male strongman athletes performed farmers' walks and deadlifts at $70 \%$ of their $1 \mathrm{RM}$ deadlift. Significant differences $(\mathrm{p}<0.05)$ were apparent at knees passing with the farmers lift demonstrating greater trunk extension, thigh angle, knee flexion and ankle dorsiflexion. Significantly greater mean vertical and anterior forces were observed in the farmers lift than deadlift. The farmers walk demonstrated significantly greater peak forces and stride rates and significantly shorter stride lengths, ground contact times, and swing times than unloaded walk. Significantly greater dorsiflexion, knee flexion, thigh angle, and significantly lesser trunk angle at foot strike were also observed in the farmers walk. The farmers lift may be an effective lifting alternative to the deadlift, to generating more anteriorpropulsive and vertical force with less stress to the lumbar spine due to the more vertical trunk position.
\end{abstract}

Keywords: Biomechanics, kinematics; kinetics; strongman; resistance training 


\section{INTRODUCTION}

Strongman is a sport similar to weightlifting, bodybuilding and power lifting in which weight training is the primary form of training [1]. The farmers walk is a popular strongman event, used in training and in competitions, that requires athletes to pick up a heavy load (in a motion similar to the deadlift) in each hand and then walk a set distance, generally between $20-50 \mathrm{~m}$ as quickly as possible [1]. The farmers walk would appear to require high anteriorposterior as well as vertical force production and may involve periods of unilateral and bilateral ground contact. In contrast, traditional weight training movements such as the deadlift are predominantly bilateral with the load being moved vertically. Corcoran and Bird [2] have suggested that strongman type exercises such as the farmers walk are ideal exercises (as a supplement to traditional power training approaches) for transferring previously attained strength gains into more 'functional strength'.

The farmers walk challenges the whole musculoskeletal system in terms of strength, stability, and physiological demands as it requires a very strong grip and core along with forceful triple extension of the ankle, knee and hip in the lifting and walking phases. The unique challenges associated with the farmers walk and its perceived benefits (improved total body and grip strength, gait loading pattern, trunk, knee, ankle and shoulder conditioning, dynamic core strength and stability and improved foot speed) may help explain its use as a conditioning method among strength and conditioning coaches [2-4]. However a mechanical understanding of the farmers walk is limited.

Only two studies have examined the biomechanical (kinematic determinants of performance and lower back/hip loads) demands of the farmers walk [5, 6]. McGill and colleagues [6] examined trunk muscle activation and lumbar spine motion, load, and stiffness in three 
strongman competitors and made comparisons in the different strongman events e.g. the farmers walk, tire flip, Atlas stones, log lift, and yoke walk. The walking events (i.e. farmers walk, yoke walk, left and right hand suitcase carry) were found to have greater activation of the abdominals (rectus abdominis, internal and external obliques), which occurred during the walking rather than lift phase, whereas the lower erector spinae peaked during the lift. McGill [7] proposed that asymmetric carries such as unilateral farmers walk (referred to as the suitcase carry) would assist many athletes in training the torso brace and strength to support the hips, pelvis and spine.

Keogh and colleagues [5] examined the kinematics of the farmers walk with five male strongman athletes who carried $90.5 \mathrm{~kg}$ in each hand for three trials of $20 \mathrm{~m}$. Sagittal plane 2D video analysis of the farmers walk showed velocity-dependent changes in kinematics similar to that seen in resisted [8] and body weight sprinting [9], whereby significant increases in step length and step rate and decreases in contact time were observed when comparing the initial $(0-3 \mathrm{~m})$ to latter stages $(8.5-11.5 \mathrm{~m}$ and $17-20 \mathrm{~m})$. Significant differences were observed between stages at foot strike and toe off, with the initial stage $(0$ $3 \mathrm{~m}$ ) demonstrating greater ankle dorsiflexion, and greater knee and thigh flexion angles and smaller ranges of motion $(\mathrm{ROM})$ than the latter stages. Interestingly, fewer significant kinematic differences were found between the fastest and slowest trials. Keogh et al. [5] postulated that success in the farmers walk may be attributed to the ability to produce high levels of anterior-posterior propulsive impulses over short contact times. However, as the study of Keogh et al. [5] was purely kinematic in nature, such an assertion requires kinetic data to be collected. 
While Keogh et al. [5] and McGill et al. [6] provided some kinematic description and kinetic data of lower back/hip loads of the farmers walk, their choice of loads were somewhat arbitrary and neither reported the ground reaction forces for this event. Since the farmers walk is becoming more widely used by strength and conditioning coaches as a means of performance enhancement [3], it is important for coaches to have data on the kinematics and kinetics of this event to understand the potential stresses this event places on the body. Such data would give coaches a greater understanding of the acute stresses that the farmers walk imposes on the system and the likely chronic adaptations to this form of training.

The purpose of this study therefore, was to examine the kinetic and kinematic characteristics of the farmers walk (i.e. the lift and walk) and make comparisons with the conventional deadlift and unloaded walk. The conventional deadlift was chosen for comparison as this movement is the most commonly performed deadlift utilised by strongman athletes [1] and is comparable to the pick-up phase of the farmers walk. Such an analysis may also help equate loading and time under tension in future training studies wishing to compare the farmers walk versus the conventional deadlift exercise on aspects of muscular function and performance. Unloaded walking was chosen for comparison to help best show the differences between loaded and unloaded gait kinematics and kinetics. It was hypothesised that the kinematics and kinetics of picking up the farmers walk bars (called the farmers lift) would share many similarities with the conventional deadlift and that the walking phase of the farmers walk would be similar to unloaded walking but exhibit forces of greater magnitudes. 


\section{METHODS}

\section{EXPERIMENTAL APPROACH TO THE PROBLEM}

A cross-sectional descriptive design was used to quantify and compare the kinematics and kinetics of the farmers walk, conventional deadlift and unloaded walk. The participants were well-trained strongman athletes with extensive experience performing the traditional and strongman lifts. Data were collected for each participant over two sessions separated by one week. Session 1 was performed in the strength and conditioning laboratory and involved 1repetition maximum (1RM) testing in the deadlift. Session 2 was performed in the biomechanics laboratory where participants performed repetitions of the deadlift, unloaded walking and the farmers walk (respectively) on force plates using loads of the deadlift 70\%1RM. Kinematics and kinetics were recorded during the second session.

\section{PARTICIPANTS}

Six male strongman athletes (four national and two regional level athletes) volunteered to participate in this study, a summary of the participant's characteristics is presented in Table 1. All participants regularly performed $1 \mathrm{RM}$ testing as part of their training and had an extensive strength training background; including experience with the squat, deadlift, clean and jerk and strongman events including the farmers walk. The study was conducted two weeks before a regional strongman competition where the majority of athletes were at the end of a training cycle aimed at improving their previous competition performance. To be eligible to participate in this study the strongman athletes had to have at least 2-years of strongman training experience, competed in at least one strongman competition and be injury free. Prior to participation, all aspects of the research were verbally explained to each participant, written informed consent was obtained and a coded number was assigned to each participant to ensure the data remained anonymous. Full ethical approval for human subject research was 
granted for all procedures used in this study by the Auckland University of Technology Ethics Committee (12/311).

\section{ONE-REPETITION MAXIMUM TESTING}

No supportive aids beyond the use of a weightlifting belt and chalk were permitted during the test. The warm up, loading increments and rest periods used were according to previously established protocols [10]. Maximum strength was assessed by a 1RM performed with a free-weight Olympic-style barbell. The alternate grip (cradle grip) was used by strongman athletes for 1RM deadlift testing. Completed lifts in the deadlift were recognised when the participants were standing still and fully upright with the applied load.

\section{DEADLIFT AND FARMERS WALK TESTING}

Before performing the lifts, participants engaged in a self-selected total body dynamic warmup similar to their specific weight training and competition warm-up procedures. Generally this began with two light sets of each lift (e.g., <40\%1RM) for 6-10 repetitions. All the participants then performed testing loads of each exercise before any data collection. Loading for the farmers walk was the athletes' $70 \% 1 \mathrm{RM}$ deadlift. Participants were asked to selfselect their movement speed for the farmers walk and deadlift. For the farmers walk participants were instructed to pick up the bars in each hand and walk forward at their typical training pace. Before specific testing occurred, participant's unloaded walk data (at their typical walking speed) was also recorded for data comparison. Typical gait and farmers walk training pace speeds were analysed as these movements accurately depict the natural kinematics and kinetics of how these events are most commonly performed. Each participant performed two trials starting on the force plate and two trials starting $3 \mathrm{~m}$ behind the force plate. Participants were allocated a 2-minute rest period between trials. A longer rest period 
of up to 5-minutes was made available between trials if the athlete felt fatigued. Consistent verbal encouragement was provided during testing sessions. The participant's best lifts and farmer's walks (determined by the participant's) were used for analysis. The farmers bars (14.3 kg, length $1160 \mathrm{~mm}$, handle thickness of $33 \mathrm{~mm}$ diameter) used in this study were purchased from Getstrength, Auckland. Shoes worn by participants during testing were those that were typically worn in their strongman training.

\section{INSTRUMENTATION}

Twelve markers were bilaterally placed over the base of the third metatarsal, lateral malleoli, lateral femoral condyles, greater trochanter, anterior superior iliac spine and superior boarder of the acromion process. Two Sony HDR - CX 190E cameras (Tokyo, Japan) were used to track the coordinates of reflective markers adhered to the body, during the various trials at a sample rate of $60 \mathrm{~Hz}$. A Bertec force plate (Model AM6501, Bertec Corp., Columbus, OH, USA) was used to collect synchronized ground reaction forces at $1000 \mathrm{~Hz}$. A diagrammatic representation of the two cameras and force platform set-up is presented in Figure 1. Vicon Nexus (Version 1.8.1, Vicon Inc., Denver, CO, USA) was used to process the ground reaction force data. Ground reaction force data were filtered using a fourth order low-pass digital Butterworth filter with a cut-off frequency of $6 \mathrm{~Hz}$.

Insert Figure 1 about here

\section{DATA ANALYSIS}

Two linear kinematic (average velocity and stride length), three temporal (stride rate, ground contact time and swing time) and four segment/joint angle (trunk, thigh, knee and ankle) variables were calculated. Gait angles were recorded at foot strike and toe-off (Figure 2) and 
lift angles were recorded at lift off (point at which load had left the ground), knees passing (point at which hands and bar/s passed the knees), and lift completion (maximal point of concentric lift) (Figure 3).

Insert Figures 2 and 3 about here

For the purposes of this study the farmers walk was analysed in 2 phases (i.e. farmers lift and farmers walk). The trunk and thigh angles were measured in absolute angles in relation to the horizontal and vertical axis (respectively) while the knee and ankle were relative (joint angles) [5]. A general measure of the range of motion (ROM) of these joint/segments was obtained by subtracting the angle at toe off from that at foot strike, and lift off from lift completion. 2D kinematics for the trunk, thigh, knee and ankle angles were calculated for the right side and were analysed in Kinovea (version 0.8.15, www.kinovea.org) (intra-rater reliability ICC $=0.96-0.99[11])$. Linear kinematics and temporal values were analysed in Vicon Nexus. Force data was normalised for time using ensemble averaging in Microsoft Excel 2007 and presented as peak and mean values. Forces in the $\mathrm{X}$ and $\mathrm{Y}$ axis were calculated as medial (positive) and lateral (negative), and anterior (propulsive ${ }^{+}$) and posterior (braking-). Sum of mean forces in the $\mathrm{X}$ and $\mathrm{Y}$ axes were calculated as the total mean (e.g. $\mathrm{X}$ $=$ medial + lateral forces). A definition for all the kinematic and temporal variables (adapted from Keogh et al. [5]) is given below.

Average Velocity $\left(\mathrm{m} . \mathrm{s}^{-1}\right)$ : The total displacement of the movement divided by the time taken.

Stride length (m): Horizontal distance from heel strike of the first foot contact to the next heel strike contact of the same foot.

Stride rate $(\mathrm{Hz})$ : The number of strides per second.

Ground contact time (s): Time from heel strike to toe off of the same foot. 
Swing time (s): Time from toe off to heel strike of the same foot.

Trunk angle $\left({ }^{\circ}\right)$ : The internal angle subtended from shoulder and hip to the horizontal axis, with larger values indicating greater trunk extension.

Thigh angle $\left({ }^{\circ}\right)$ : The internal angle subtended from knee and hip to the vertical axis, with positive values indicating that the thigh was anterior to the hip.

Knee angle $\left({ }^{\circ}\right)$ : The internal angle subtended from the hip, knee and ankle markers, with $180^{\circ}$ indicating full knee extension.

Ankle angle $\left({ }^{\circ}\right)$ : The internal angle subtended from the knee, ankle and toe, with increasing values indicating plantarflexion.

\section{STATISTICAL ANALYSIS}

Means and standard deviations were used as measures of centrality and spread of data. Two-tailed paired t-tests were used to determine if any statistical differences existed in kinematics and ground reaction forces between the farmers lift and deadlift, and the farmers walk and unloaded walk. Statistical significance was set at $p \leq 0.05$. All analyses were performed using IBM Statistical Package for the Social Sciences (Version 20.0, SPSS for Windows). 


\section{RESULTS}

Descriptive characteristics of all strongman athletes are presented in Table 1. On average strongman athletes trained four times a week for ninety minutes per session which totalled $6.4 \mathrm{hrs}$ of strongman/resistance training per week.

Insert Table 1 about here

\section{LIFTING KINEMATICS BETWEEN THE FARMERS LIFT AND DEADLIFT}

Participants demonstrated a greater stance width in the deadlift $(38.9 \pm 4.5 \mathrm{~cm} ; \mathrm{p}=0.0028)$ compared to the farmers lift $(26.3 \pm 4.7 \mathrm{~cm})$. Significant differences were observed in trunk angles between the deadlift and farmers lift, with the deadlift trunk angle being more horizontal at lift off (LO), and knees passing (KP) and more vertical at lift completion (LC) (see Table 2). The farmers walk and deadlift were found to differ significantly during KP for all angles, however, relatively few significant differences were observed for the ROM, LO and LC (Table 2).

Insert Table 2 about here

\section{LIFTING KINETICS BETWEEN THE FARMERS LIFT AND DEADLIFT}

The farmers lift was found to have significantly higher mean vertical $(2893 \pm 442 \mathrm{~N}$ versus $2679 \pm 471 \mathrm{~N})$, mean anterior forces $(66 \pm 23 \mathrm{~N}$ versus $42 \pm 15 \mathrm{~N})$ and the sum of mean anterior-propulsive forces $(38 \pm 20 \mathrm{~N}$ versus $1 \pm 4 \mathrm{~N})$ compared to the deadlift (Table 3). While the lift times of the deadlift were significantly longer than the farmers lift $(1.81 \pm 0.24$ $\mathrm{s}$ versus $0.92 \pm 0.29 \mathrm{~s})$, peak vertical velocity was significantly higher in the deadlift $(0.76 \pm$ 
$0.15 \mathrm{~m} \cdot \mathrm{s}^{-1}$ versus $0.44 \pm 0.17 \mathrm{~m} \cdot \mathrm{s}^{-1}$ ), potentially due to the greater vertical displacement of the bar.

Insert Table 3 about here

Pictorial representations of group mean ground reaction force curves (normalised to percentage of mean lift time) for the deadlift and farmers lift are presented in Figure 4. Similarities can be observed in the shape of the force-time curves between the deadlift and farmers lifts in the lifting phases.

Insert Figure 4 about here

\section{GAIT KINEMATIC OF THE FARMERS WALK AND UNLOADED WALK}

Significant differences were found between the farmers walk and unloaded walk at $1^{\text {st }}$ stride and at $3-4 \mathrm{~m}$ with the farmers demonstrating greater stride rates (48\% and $61 \%$ greater), but lower stride lengths (36\% and 27\% less), ground contact times (both $31 \%$ less) and swing times (both $46 \%$ less) (respectively) (see Table 4). The farmers walk at $3-4$ m demonstrated the greatest average velocity $\left(1.48 \pm 0.19 \mathrm{~m} \cdot \mathrm{s}^{-1}\right)$. Significant kinematic differences were observed between the farmers walk and unloaded walk at foot strike $\left(1^{\text {st }}\right.$ stride and $\left.3-4 \mathrm{~m}\right)$ and toe off (at $3-4 \mathrm{~m}$ ) for many joint and segment angles with the farmers walk demonstrating greater trunk flexion $\left(69^{\circ}\right.$ and $78^{\circ}$ versus $84^{\circ}$ and $\left.90^{\circ}\right)$, knee flexion $\left(154^{\circ}\right.$ and $117^{\circ}$ versus $177^{\circ}$ and $121^{\circ}$ ), and ankle dorsiflexion $\left(95^{\circ}\right.$ and $105^{\circ}$ versus $105^{\circ}$ and $\left.108^{\circ}\right)$. A pictorial representation of the farmers walk and unloaded walk at heel strike and toe off is presented in Figure 5. Greater trunk flexion, reduced stride length and greater knee flexion at FS are clearly demonstrated in the farmers compared to unloaded walk. 
Insert Table 4 and Figure 5 about here

WALKING KINETICS BETWEEN THE FARMERS WALK AND UNLOADED WALK (3 $4 M)$

The farmers walk produced significantly greater peak and mean vertical $(240 \%$ and $247 \%$ greater), peak and mean anterior (172\% and $153 \%$ greater), peak and mean posterior (184\% and $169 \%$ greater) and peak and mean medial (200\% and $176 \%$ greater) and peak lateral forces $(176 \%$ greater) than unloaded walk (respectively) (Table 5). Interestingly no significant differences were found in mean lateral forces between the loaded and unloaded conditions.

Insert Table 5 about here

Group mean average force-time curves (normalised to percentage of mean lift time) obtained with unloaded walk and the farmers walk are presented in Figure 6. Although the shape of the force-time curves of the farmers walk and unloaded walk are similar, greater magnitudes of force are clearly observed in the farmers walk.

Insert Figure 6 about here 


\section{DISCUSSION}

Since the farmers walk is becoming more widely used by coaches in strength and conditioning practice as a means of performance enhancement [3], the aim of this study was to gain a greater understanding of the acute stresses that the farmers walk imposes on the system and the likely chronic adaptations to this form of training. To achieve this, the kinetic and kinematic characteristics of the farmers walk (i.e. the lift and walk) were quantified and compared with the two comparable movements, the deadlift and unloaded walk. Significant kinematic and kinetic differences were observed between the lifting (i.e. the farmers lift and deadlift) and walking (farmers walk and unloaded walk) conditions. The peak vertical ground reaction forces of the deadlift and farmers lift $(3175 \pm 494 \mathrm{~N}$ and $3215 \pm 508 \mathrm{~N}$ respectively) were comparable to those reported for powerlifters performing the hexbar deadlift and conventional deadlift with similar relative loads (70\% 1RM) [12]. Significantly greater mean vertical force $(2893 \pm 442 \mathrm{~N}$ versus $2679 \pm 471 \mathrm{~N})$, mean anterior force $(66 \pm 23 \mathrm{~N}$ versus 42 $\pm 15 \mathrm{~N})$ and sum of anterior-posterior forces $(38 \pm 20 \mathrm{~N}$ versus $1 \pm 4 \mathrm{~N})$ were observed in the farmers lift than the deadlift. The higher forces associated with the farmers lift are similar to the findings of Swinton et al. [12] who found that lifts performed with the hexagon barbell deadlift produced consistently higher forces than the conventional deadlift with the same loads $(20 \%$ to $80 \% 1 \mathrm{RM})$. The greater mean forces in the farmers lift than deadlift may reflect the higher handle grips of the farmers bars and the associated significant kinematic differences. Specifically, the deadlift trunk angle was significantly more horizontal $(65 \%$ less) at lift off and knees passing and significantly more vertical (36\% greater) at lift completion compared to the farmers lift. The differences at lift completion reflect the hyperextension of the trunk associated with the end of the concentric phase of the deadlift $\left(99.8 \pm 7.4^{\circ}\right)$ whereas the angle at completion of the farmers lift $\left(73.5 \pm 8.6^{\circ}\right)$ reflected the need to take the first step of the farmers walk. Significantly greater ankle dorsiflexion, knee 
flexion, thigh extension and a more vertical trunk angle were found at knee passing for the farmers lift as opposed to the deadlift.

Deadlift kinematics in the present study, were similar to those reported for powerlifters [13] with stance width and relative knee and absolute trunk angles at lift off. Slight differences in knee and trunk angles were apparent at knee passing, which may be a result of the different loads used in these studies (e.g. 70\%1RM vs $1 \mathrm{RM}$ ) $[12,14]$. Interestingly, the kinematics of the farmers lift appears more similar to the sumo deadlift than the conventional deadlift. A three-dimensional biomechanical analysis of sumo and conventional style deadlifts [14] found that, like the farmers lift, the sumo group maintained a more upright trunk and demonstrated greater hip and knee flexion at knees passing, whereas the conventional group positioned the shank closer to the vertical.

Swinton and colleagues [12] found that deadlift performed with a hexagon barbell (also known as a trap bar) significantly reduced the moment arm at the lumbar spine, hip and ankle. The lifting kinematics and kinetics of the farmers lift may have some advantages over the conventional deadlift as an effective lifting alternative especially for athletes with a history of lower back pain or currently in the final stages of rehabilitation. Recent research on the injury epidemiology of strongman athletes [15] found that the deadlift was associated with the highest amount of lower back injuries among all traditional and strongman exercises performed by 174 strongman athletes. In contrast only three lower back injuries were associated with the farmers walk.

The present study sought to provide further insight into the farmers walk by providing kinematic and kinetic data of loaded carrying versus unloaded gait. Significantly shorter 
stride lengths', ground contact times and swing times and significantly higher stride rates, were associated with the farmers walk. Such results were expected as participants performed the farmers walk at 'training speed' which is faster than their preferred unloaded gait speed. Successful performance in the farmers walk is based on the fastest time to complete the event. Interestingly, the stride rate reported in this study $(1.42 \mathrm{~Hz})$ for the farmers walk (at 3 $-4 \mathrm{~m})$ was higher than those reported $(1.10-1.38 \mathrm{~Hz})$ for running at $1.65-4.00 \mathrm{~m} \cdot \mathrm{s}^{-1}[16$, 17]. It is quite likely that like sprinters (at higher speeds); strongman athletes increase their velocity by increasing their stride rate more than their stride length. Cooke et al. [18] suggested that a shortening of stride length may be responsible for an improvement in economy with vertical loading as it may lead to a reduction in the vertical oscillation of the system's centre of mass.

The farmers walk (at $3-4 \mathrm{~m}$ ) was found to have significantly greater dorsiflexion $(95.4 \pm 2.7$ ${ }^{\mathrm{o}}$ vs $\left.105.2 \pm 2.4^{\circ}\right)$, knee flexion $\left(154.4 \pm 6.5^{\circ}\right.$ vs $\left.177.6 \pm 6.0^{\circ}\right)$, thigh angle $\left(33.8 \pm 5.9^{\circ}\right.$ vs 22.8 $\left.\pm 6.7^{\circ}\right)$, and significantly lesser trunk angle $\left(77.8 \pm 3.3^{\circ}\right.$ vs $\left.89.6 \pm 2.4^{\circ}\right)$ at foot strike than unloaded gait (at $3-4 \mathrm{~m}$ ). Greater dorsiflexion at the ankle was attributed to a lesser stride length than unloaded walk and a more vertical shank segment angle. Collectively, these data indicate all three joints (ankle, knee and hip) are flexed more at foot strike in the farmers than unloaded walk. Such a strategy may help reduce braking forces and provide a more optimal position to generate propulsive forces from foot strike based on the muscles being at a more favourable length to take advantage of the length-tension relationship. Mean braking forces seen in the present study were only $41 \%$ greater in the farmers walk compared to unloaded walk, even though their system mass (body plus farmers bars) was close to 2.5 times their bodyweight. 
Comparable flexion angles $\left({ }^{\circ}\right)$ were seen in this study (at $\left.3-4 \mathrm{~m}\right)$ in the thigh $\left(34 \pm 6^{\circ}\right.$ vs 32 $\left.\pm 3^{\circ}\right)$, knee $\left(154 \pm 7^{\circ}\right.$ vs $\left.150 \pm 6^{\circ}\right)$ and ankle $\left(95 \pm 3^{\circ}\right.$ vs $\left.100 \pm 8^{\circ}\right)$ at foot strike to that of Keogh and colleagues [5] (at $0-3 \mathrm{~m}$ ) in which five male athletes completed three $20 \mathrm{~m}$ farmers walk trials. Interestingly, average velocity $\left(1.48 \pm 0.17 \mathrm{~m} \cdot \mathrm{s}^{-1} \mathrm{vs} 2.41 \pm 0.32 \mathrm{~m} \cdot \mathrm{s}^{-1}\right)$, stride length $(1.05 \pm 0.11 \mathrm{~m}$ vs $1.35 \pm 0.12 \mathrm{~m})$, stride rate $(1.42 \pm 0.17 \mathrm{~Hz}$ vs $1.79 \pm 0.14 \mathrm{~Hz})$, ground contact time $(0.46 \pm 0.06 \mathrm{~s}$ vs $0.36 \pm 0.04 \mathrm{~s})$, and swing time $(0.25 \pm 0.02 \mathrm{~s}$ vs $0.20 \pm$ $0.02 \mathrm{~s}$ ) in the present study were considerably less at $3 \mathrm{~m}$ than those reported by Keogh and colleagues [5]. Loading (70\%1RM versus $90.5 \mathrm{~kg}$ ) and environmental factors (laboratory versus outdoors course), coupled with the instructions for the participants to maintain 'good form at training pace' may explain the differences observed in this study.

Interestingly, the shape of the force-time profiles associated with the farmers walk were very similar to unloaded walk. A significant loading effect was however evident in ground reaction forces, with significantly greater peak and mean forces observed in all three axes during the farmers walk. The vertical forces in the farmers walk (with very heavy loads $-70 \%$ 1RM deadlift), were similar to those reported for running ( 2.8 and 2.3 bodyweights at $4.5 \mathrm{~m} \cdot \mathrm{s}^{-}$ ${ }^{1}$ and $\left.5.0 \mathrm{~m} \cdot \mathrm{s}^{-1}\right)[19,20]$.

Peak anterior-propulsive forces and peak posterior braking forces were 1.72 and 1.84 times greater in the farmers walk than unloaded walk. Similar increases in horizontal force have been reported for sprint kinetics as running velocity increased from moderate to high maximum values $[21,22]$. The results of this study support the contention of Keogh and colleagues [5] that success in the farmers walk could be related to the ability to produce high levels of vertical and anterior-posterior propulsive impulses over short ground contact times. 
Studies are needed to investigate the effect of farmers walk velocity and load on anteriorposterior propulsive ground reaction force values.

The magnitudes of forces in the medial-lateral direction of the farmers walk and unloaded walk were comparatively smaller than those of the anterior-posterior or vertical components. An interesting finding in this study was that mean lateral forces although substantially greater in the farmers walk, were not significantly different to the unloaded walk. Large variances have been associated in the medial-lateral direction among individual runners [20], which is similar to the findings of this study.

\section{CONCLUSION}

The results of this study provide coaches with the first biomechanical description of the farmers walk and provide insight into its kinetic and kinematic determinants. The farmers lift may have advantages over the conventional deadlift as an effective lifting alternative to generating more anterior-propulsive and vertical force with less apparent stress to the lumbar spine due to the more vertical trunk position. The farmers walk generated significantly higher vertical, anterior-propulsive and medial lateral forces in a characteristic gait pattern than unloaded walking. Such findings suggest that the farmers walk could prove to be an efficient mechanical stimulus to enhance various aspects of the gait cycle. Neuromuscular adaptations such as improvements in the production of anterior-propulsive forces, ankle strength and stability, lower body kinetic chain development, and core strength and stability may result from the inclusion of the farmers walk in resistance training programmes. However, longitudinal training studies are needed to validate such views. 
Biomechanical Analysis of the Farmers Walk

\section{ACKNOWLEDGEMENTS}

The authors would like to thank each of the strongman athletes who participated in this study and Anna Lorimer for her help with data collection. 
Biomechanical Analysis of the Farmers Walk

\section{REFERENCES}

1. Winwood PW, Keogh JWL, and Harris NK., The Strength and Conditioning Practices of Strongman Competitors, Journal of Strength and Conditioning Research, 2011, 25(11), 3118-28.

2. Corcoran G, and Bird S., Preseason Strength Training for Rugby Union: The General and Specific Preparatory Phases, Strength and Conditioning Journal, 2009, 31(6), 66-74.

3. Winwood PW, Cronin JB, Dudson MK, Gill ND, and Keogh JWL., How Coaches Use Strongman Implements in Strength and Conditioning Practice, International Journal of Sports Science \& Coaching, In Press.

4. Poliquin C, and McDermott A., Applied Strongman Training for Sport - Theory and Technical, Nevada City, CA, Ironmind Enterprizes Inc, 2005.

5. Keogh J, Kattan A, Logan S, Bensley J, Muller C, and Powell L., A Preliminary Kinematic Gait Analysis of a Strongman Event: The Farmers Walk, Sports, 2014, 2, 24-33. 6. McGill SM, McDermott A, and Fenwick CMJ., Comparison of Different Strongman Events: Trunk Muscle Activation and Lumbar Spine Motion, Load, and Stiffness, Journal of Strength and Conditioning Research, 2009, 23(4), 1148-61.

7. McGill S., Core Training: Evidence Translating to Better Performance and Injury Prevention, Strength and Conditioning Journal, 2010, 32(3), 33-46.

8. Keogh JWL, Newlands C, Blewett S, Payne A, and Chun-Er L, A Kinematic Analysis of a Strongman Event: The Heavy Sprint-Style Sled pull, Journal of Strength and Conditioning Research, 2010, 24(11), 3088-97.

9. Hunter JP, Marshall RN, and McNair PJ., Interaction of Step Length and Step Rate During Sprint Running, Medicine \& Science in Sports \& Exercise, 2004, 36, 261-71.

10. Wilson G., Strength and Power Assessment. Applied Anatomy and Biomechanics in Sport, Melbourne, Blackwell Scientific Publications, 1994.

11. Bowerman E, Whatman C, Harris N, and Bradshaw E., Reliability of 2D Lower Extremity Alignment Measures in Elite Adolescent Ballet Dancers, $\underline{\text { New Zealand Journal of }}$ Sports Medicine, 2013, 40(2), 70-3.

12. Swinton PA, Stewart A, Agouris I, Keogh JWL, and Lloyd R., A Biomechanical Analysis of Straight and Hexagonal Barbell Deadlifts Using Submaximal Loads, Journal of Strength \& Conditioning Research, 2011, 25(7).

13. Escamilla RF, Lowry TM, Osbahr DC, and Speer KP., Biomechanical Analysis of the Deadlift During the 1999 Special Olympics World Games, Medicine \& Science in Sports \& Exercise, 2001, 33 (8), 1345-53. 
14. Escamilla RF, Francisco AC, Fleisig GS, Barrentine SW, Welch CM, Kayes AV, et al., A Three-Dimensional Biomechanical Analysis of Sumo and Conventional Style Deadlifts, Medicine \& Science in Sports \& Exercise, 2000, 32(7), 1265-75.

15. Winwood PW, Hume PA, Cronin JB, and Keogh JWL., Retrospective Injury Epidemiology of Strongman Athletes, Journal of Strength \& Conditioning Research, 2014, 28(1), 28-42.

16. Ōnpuu S., The Biomechanics of Walking and Running, Clinics in Sports Medicine, 1994, 13(4), $843-63$.

17. Luhtanen P, and Komi PV., Mechanical Factors Affecting Running Speed, In: Asmussen E, Jorgensen K, editors, Biomechanics VI-B, Baltimore, University Park Press, 1973, 23-9.

18. Cooke CB, McDonagh MJN, Nevill AM, and Davies CTM., Effects of Load on Oxygen Intake in Trained Boys and Men During Treadmill Running, Journal of Applied Physiology, 1991, 71, 1237-44.

19. Munro CF, Miller DI, and Fuglevand AJ., Ground Reaction Forces in Running: A Reexamination, Journal of Biomechanics, 1987, 20(2), 147-55.

20. Cavanagh PR, and Lafortu MA., Ground Reaction Forces in Distance Running, Journal of Biomechanics, 1980, 13, 397-406.

21. Kyrolainen H, Belli A, and Komi PV., Biomechanical Factors Affecting Running Economy, Medicine \& Science in Sports \& Exercise, 2001, 33, 1330-7.

22. Brughelli M, Cronin J, and Chaouachi A., Effects of Running Velocity on Running Kinetics and Kinematics, Journal of Strength and Conditioning Research, 2011, 25(4), 933-9. 


\section{Figure Legends}

Figure 1: Sony Camera and Force Platform Set Up .28

Figure 2: Pictorial Representation of the Four Angles Measured in the 2D Analysis of Farmers Walk. The Top Row From Left to Right Depicts the Ankle, Knee, Hip and Trunk Angles at Foot Strike and the Bottom Row at Toe Off.

Figure 3: Pictorial Representation of the Four Angles Measured at LO, KP and LC (From Left to Right) in the Farmers Lift (top row) and Deadlift (bottom row)

Figure 4: Group Mean Vertical (top), Anterior/Posterior (middle) and Medial/Lateral (bottom) Force-Time Curves (Normalised to Percentage of Mean Lift Time) Obtained With a $70 \%$ 1RM Load.

Figure 5: Pictorial Representation of Differences Between the Farmers Walk and Unloaded Walk at Heel Strike (left) and Toe Off (right) at $3-4 \mathrm{~m}$ .32

Figure 6: Group Mean Vertical (Top), Anterior/Posterior (Middle) and Medial/Lateral (Bottom) Average Vertical Force-Time Curves (Normalised to Percentage of Mean Lift Time) Obtained with Unloaded Walk at 3 - 4 m and the Farmers Walk With 70\% 1Repetition Maximum Load at 3 - 4 m. Graphs Depict Loading Response From Heel Strike to Heel Strike for One Stride (i.e. Two Steps)

\section{Table Legends}

Table 1: Demographics, Training Characteristics and Strength Measures (mean \pm SD) for Strongman Athletes.

Table 2: Kinematics of Trunk, Thigh, Knee and Ankle Angles Performed During the Concentric Lifting Phase of the Two Exercises.....

Table 3: Kinematics and Kinetics of the Deadlift and Farmers Lift .25

Table 4: Differences in Gait Kinematic Between the Farmers Walk and Unloaded Walk ....26

Table 5: Kinetics of Unloaded and Farmers Walk (3-4 m) 
Table 1: Demographics, Training Characteristics and Strength Measures (mean \pm SD) for Strongman Athletes

All Strongman athletes

$(\mathrm{n}=6)$

\begin{tabular}{ll}
\hline Demographics & \\
Age $(\mathrm{y})$ & $24.0 \pm 3.9$ \\
Height $(\mathrm{cm})$ & $181.6 \pm 9.4$ \\
Body mass $(\mathrm{kg})$ & $112.9 \pm 28.9$ \\
\hline Training & \\
Resistance training experience (y) & $6.5 \pm 2.7$ \\
Strongman implement training experience (y) & $2.7 \pm 1.6$ \\
Number of resistance training sessions per week & $4.2 \pm 1.2$ \\
Average time of resistance training sessions (min) & $90.8 \pm 30.4$ \\
\hline Strength & \\
Deadlift 1RM $\left(\mathrm{kg}^{2}\right)$ & $238.3 \pm 22.3$ \\
Deadlift $1 \mathrm{RM}\left(\mathrm{kg} k g^{-1}\right)$ & $2.19 \pm 0.39$ \\
\hline
\end{tabular}


Table 2: Kinematics of Trunk, Thigh, Knee and Ankle Angles Performed During the Concentric Lifting Phase of the Two Exercises

\begin{tabular}{|c|c|c|}
\hline & Farmers Lift & Deadlift \\
\hline \multicolumn{3}{|l|}{ Lift Off $(L O)$} \\
\hline Trunk angle $\left({ }^{0}\right)$ & $40.5 \pm 4.1^{\dagger}$ & $14.0 \pm 5.7$ \\
\hline Thigh angle $\left({ }^{0}\right)$ & $47.3 \pm 4.4$ & $49.2 \pm 9.0$ \\
\hline Knee angle $\left({ }^{0}\right)$ & $105.7 \pm 4.0$ & $110.0 \pm 12.3$ \\
\hline Ankle angle $\left({ }^{0}\right)$ & $84.0 \pm 5.9$ & $88.8 \pm 5.8$ \\
\hline \multicolumn{3}{|c|}{ Knee Passing (KP) } \\
\hline Trunk angle $\left({ }^{0}\right)$ & $49.3 \pm 6.2^{\dagger 0.04}$ & $44.7 \pm 3.4$ \\
\hline Thigh angle $\left({ }^{0}\right)$ & $39.8 \pm 3.9^{\dagger}$ & $25.2 \pm 7.4$ \\
\hline Knee angle $\left({ }^{0}\right)$ & $114.0 \pm 2.5^{\dagger}$ & $144.8 \pm 7.6$ \\
\hline Ankle angle $\left({ }^{0}\right)$ & $83.8 \pm 5.3^{\dagger}$ & $101.0 \pm 5.0$ \\
\hline \multicolumn{3}{|c|}{ Lift Completion (LC) } \\
\hline Trunk angle $\left({ }^{0}\right)$ & $73.5 \pm 8.6^{\dagger 0.005}$ & $99.8 \pm 7.4$ \\
\hline Thigh angle $\left({ }^{0}\right)$ & $11.8 \pm 6.3$ & $14.7 \pm 7.6$ \\
\hline Knee angle $\left({ }^{0}\right)$ & $150.5 \pm 9.7$ & $154.0 \pm 9.6$ \\
\hline Ankle angle $\left({ }^{0}\right)$ & $90.2 \pm 7.3^{\dagger 0.04}$ & $97.7 \pm 5.2$ \\
\hline \multicolumn{3}{|c|}{ Range of Motion (ROM) } \\
\hline Trunk angle $\left({ }^{0}\right)$ & $33.0 \pm 10.7^{\dagger}$ & $85.8 \pm 10.0$ \\
\hline Thigh angle $\left({ }^{0}\right)$ & $-35.5 \pm 7.1$ & $-34.0 \pm 11.5$ \\
\hline Knee angle $\left({ }^{0}\right)$ & $44.8 \pm 13.4$ & $44.0 \pm 17.5$ \\
\hline Ankle angle $\left({ }^{0}\right)$ & $6.2 \pm 9.4$ & $8.8 \pm 8.0$ \\
\hline
\end{tabular}

Data expressed as mean \pm SD.

$\dagger$ significantly different to other level of variable $\mathrm{p}=<0.001$ unless specified.

Note: Smaller trunk, knee and ankle angles denote greater flexion. Smaller thigh angles denote greater extension. 
Table 3: Kinematics and Kinetics of the Deadlift and Farmers Lift

Deadlift

Z axis

\begin{tabular}{|c|c|c|}
\hline Peak Vertical Force $(\mathrm{N})$ & $3175 \pm 494$ & $3215 \pm 508$ \\
\hline Mean Vertical Force (N) & $2679 \pm 471^{\dagger 0.021}$ & $2893 \pm 442$ \\
\hline \multicolumn{3}{|l|}{ Y axis } \\
\hline Peak Anterior Force $(\mathrm{N})$ & $132 \pm 62$ & $184 \pm 80$ \\
\hline Mean Anterior Force (N) & $41 \pm 15^{\dagger 0.007}$ & $66 \pm 23$ \\
\hline Peak Posterior Force $(\mathrm{N})$ & $-101 \pm 34$ & $-98 \pm 38$ \\
\hline Mean Posterior Force $(\mathrm{N})$ & $-39 \pm 12$ & $-36 \pm 21$ \\
\hline Mean of $Y$ forces $(\mathrm{N})$ & $1 \pm 4^{\dagger 0.006}$ & $38 \pm 20$ \\
\hline \multicolumn{3}{|l|}{$\mathrm{X}$ axis } \\
\hline Peak Medial Force (N) & $72 \pm 19$ & $67 \pm 49$ \\
\hline Mean Medial Force (N) & $22 \pm 9$ & $19 \pm 12$ \\
\hline Peak Lateral Force (N) & $-102 \pm 55$ & $-71 \pm 29$ \\
\hline Mean Lateral Force (N) & $-23 \pm 6$ & $-21 \pm 9$ \\
\hline Mean of $X$ forces $(\mathrm{N})$ & $-1 \pm 6$ & $-2 \pm 20$ \\
\hline Peak Vertical Velocity $\left(\mathrm{m}^{-1}\right)$ & $0.76 \pm 0.15^{\dagger 0.032}$ & $0.44 \pm 0.17$ \\
\hline Concentric Lift Time (s) & $1.81 \pm 0.24^{\dagger 0.003}$ & $0.92 \pm 0.29$ \\
\hline
\end{tabular}

Data expressed as mean \pm SD.

$\uparrow$ significantly different to other level of variable $\mathrm{p}=<0.001$ unless specified. 
Table 4: Differences in Gait Kinematic Between the Farmers Walk and Unloaded Walk

\begin{tabular}{|c|c|c|c|c|}
\hline & $\begin{array}{l}\text { Farmers Walk } \\
\text { (1st Stride) }\end{array}$ & $\begin{array}{l}\text { Unloaded Walk } \\
\text { (1st Stride) }\end{array}$ & $\begin{array}{l}\text { Farmers Walk } \\
(3-4 \mathrm{~m})\end{array}$ & $\begin{array}{l}\text { Unloaded Walk } \\
(3-4 \mathrm{~m})\end{array}$ \\
\hline Average velocity $\left(\mathrm{m} \cdot \mathrm{s}^{-1}\right)$ & $1.05 \pm 0.21$ & $1.11 \pm 0.09$ & $1.48 \pm 0.19$ & $1.26 \pm 0.15$ \\
\hline Stride length (m) & $0.85 \pm 0.19^{\dagger 0.023}$ & $1.33 \pm 0.11$ & $1.04 \pm 0.12^{\dagger 0.002}$ & $1.43 \pm 0.11$ \\
\hline Stride rate $(\mathrm{Hz})$ & $1.21 \pm 0.12^{\dagger}$ & $0.82 \pm 0.04$ & $1.42 \pm 0.17^{\dagger 0.001}$ & $0.88 \pm 0.06$ \\
\hline Ground contact time (s) & $0.53 \pm 0.09^{\dagger 0.002}$ & $0.77 \pm 0.07$ & $0.46 \pm 0.06^{\dagger}$ & $0.67 \pm 0.06$ \\
\hline Swing time (s) & $0.24 \pm 0.02^{\dagger}$ & $0.44 \pm 0.02$ & $0.25 \pm 0.02^{\dagger}$ & $0.46 \pm 0.03$ \\
\hline \multicolumn{5}{|l|}{ Foot Strike (FS) } \\
\hline Trunk angle $\left({ }^{0}\right)$ & $68.5 \pm 5.2^{\dagger 0.016}$ & $85.3 \pm 1.9$ & $77.8 \pm 3.3^{\dagger 0.003}$ & $89.6 \pm 2.4$ \\
\hline Thigh angle $\left({ }^{0}\right)$ & $26.0 \pm 5.7$ & $22.8 \pm 6.5$ & $33.8 \pm 5.9^{\dagger 0.05}$ & $22.8 \pm 6.7$ \\
\hline Knee angle $\left({ }^{0}\right)$ & $150.0 \pm 9.1^{\dagger 0.033}$ & $174.0 \pm 10.2$ & $154.4 \pm 6.5^{\dagger 0.006}$ & $177.6 \pm 6.0$ \\
\hline Ankle angle $\left(^{0}\right)$ & $95.8 \pm 5.6^{\dagger 0.033}$ & $105.3 \pm 1.7$ & $95.4 \pm 2.7^{\dagger}$ & $105.2 \pm 2.4$ \\
\hline \multicolumn{5}{|l|}{ Toe Off (TO) } \\
\hline Trunk angle $\left({ }^{0}\right)$ & $70.0 \pm 4.7^{\dagger 0.030}$ & $84.0 \pm 3.5$ & $75.8 \pm 4.5^{\dagger 0.002}$ & $87.2 \pm 2.3$ \\
\hline Thigh angle $\left({ }^{0}\right)$ & $12.3 \pm 12.1$ & $7.8 \pm 7.0$ & $14.6 \pm 9.5^{\dagger 0.012}$ & $0.8 \pm 6.1$ \\
\hline Knee angle $\left({ }^{0}\right)$ & $125.3 \pm 10.1$ & $121.3 \pm 13.4$ & $117.4 \pm 11.1$ & $126.6 \pm 5.5$ \\
\hline Ankle angle $\left({ }^{0}\right)$ & $104.8 \pm 6.3$ & $117.5 \pm 4.8$ & $99.6 \pm 5.4^{\dagger 0.011}$ & $114.8 \pm 8.7$ \\
\hline \multicolumn{5}{|l|}{ Range of Motion (ROM) } \\
\hline Trunk ROM $\left({ }^{0}\right)$ & $1.5 \pm 3.3^{\dagger 0.049}$ & $-1.3 \pm 2.6$ & $-2.0 \pm 2.9$ & $-2.4 \pm 1.9$ \\
\hline Thigh ROM $\left(^{0}\right)$ & $-13.8 \pm 6.8$ & $-15.0 \pm 5.5$ & $-19.2 \pm 4.6$ & $-22.0 \pm 9.5$ \\
\hline Knee ROM $\left({ }^{0}\right)$ & $-24.8 \pm 4.5^{\dagger 0.013}$ & $-52.8 \pm 9.7$ & $-37.0 \pm 8.6$ & $-51.0 \pm 8.4$ \\
\hline Ankle ROM $\left({ }^{0}\right)$ & $9.0 \pm 9.5$ & $12.3 \pm 6.3$ & $4.2 \pm 4.3$ & $9.6 \pm 9.8$ \\
\hline
\end{tabular}

Data expressed as mean \pm SD. ${ }^{\dagger}$ Significantly different to other level of variable $p<0.001$ unless specified. Note: Smaller trunk, knee and ankle angles denote greater flexion and plantar-flexion. Smaller thigh angles denote greater extension. 
Table 5: Kinetics of Unloaded and Farmers Walk (3-4 m)

$\begin{array}{ll}\text { Unloaded Walk } & \text { Farmers Walk } \\ (1 \text { stride at } 3-4 \mathrm{~m}) & (1 \text { stride at } 3-4 \mathrm{~m})\end{array}$

\begin{tabular}{lll}
\hline \multicolumn{2}{l}{$\mathrm{Z}$ axis } & \\
\cline { 1 - 2 } Peak Vertical Force (N) & $1510 \pm 387^{\dagger}$ & $3626 \pm 608$ \\
Mean Vertical Force (N) & $1025 \pm 247^{\dagger}$ & $2536 \pm 376$ \\
\cline { 1 - 2 } Y axis & $259 \pm 53^{\dagger 0.007}$ & $447 \pm 98$ \\
\cline { 1 - 2 } Peak Anterior Force (N) & $83 \pm 25^{\dagger 0.008}$ & $127 \pm 31$ \\
Mean Anterior Force (N) & $-211 \pm 77^{\dagger 0.017}$ & $-389 \pm 143$ \\
Peak Posterior Force (N) & $-94 \pm 34^{\dagger 0.003}$ & $-159 \pm 45$ \\
Mean Posterior Force (N) & $-12 \pm 12$ & $-32 \pm 40$ \\
Mean of Y forces (N) & $120 \pm 62^{\dagger 0.022}$ & $241 \pm 73$ \\
\cline { 1 - 2 } X axis & $70 \pm 36^{\dagger 0.042}$ & $120 \pm 41$ \\
\cline { 1 - 2 } Peak Medial Force (N) & $-119 \pm 45^{\dagger 0.019}$ & $-210 \pm 73$ \\
Mean Medial Force (N) & $-65 \pm 29$ & $-106 \pm 31$ \\
Peak Lateral Force (N) & $5 \pm 11$ & $13 \pm 28$ \\
Mean Lateral Force (N) & & \\
Mean of X forces (N) & &
\end{tabular}

Data expressed as mean \pm SD.

$\dagger$ significantly different to other level of variable $p=<0.001$ unless specified. 
Biomechanical Analysis of the Farmers Walk

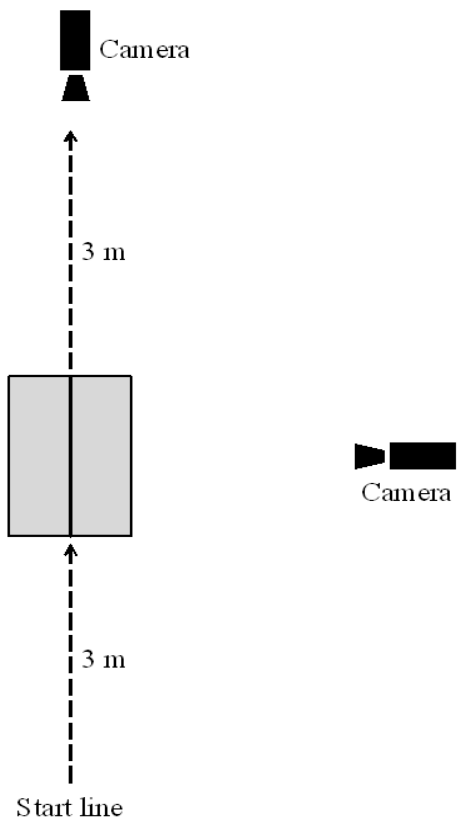

Figure 1: Sony Camera and Force Platform Set Up 


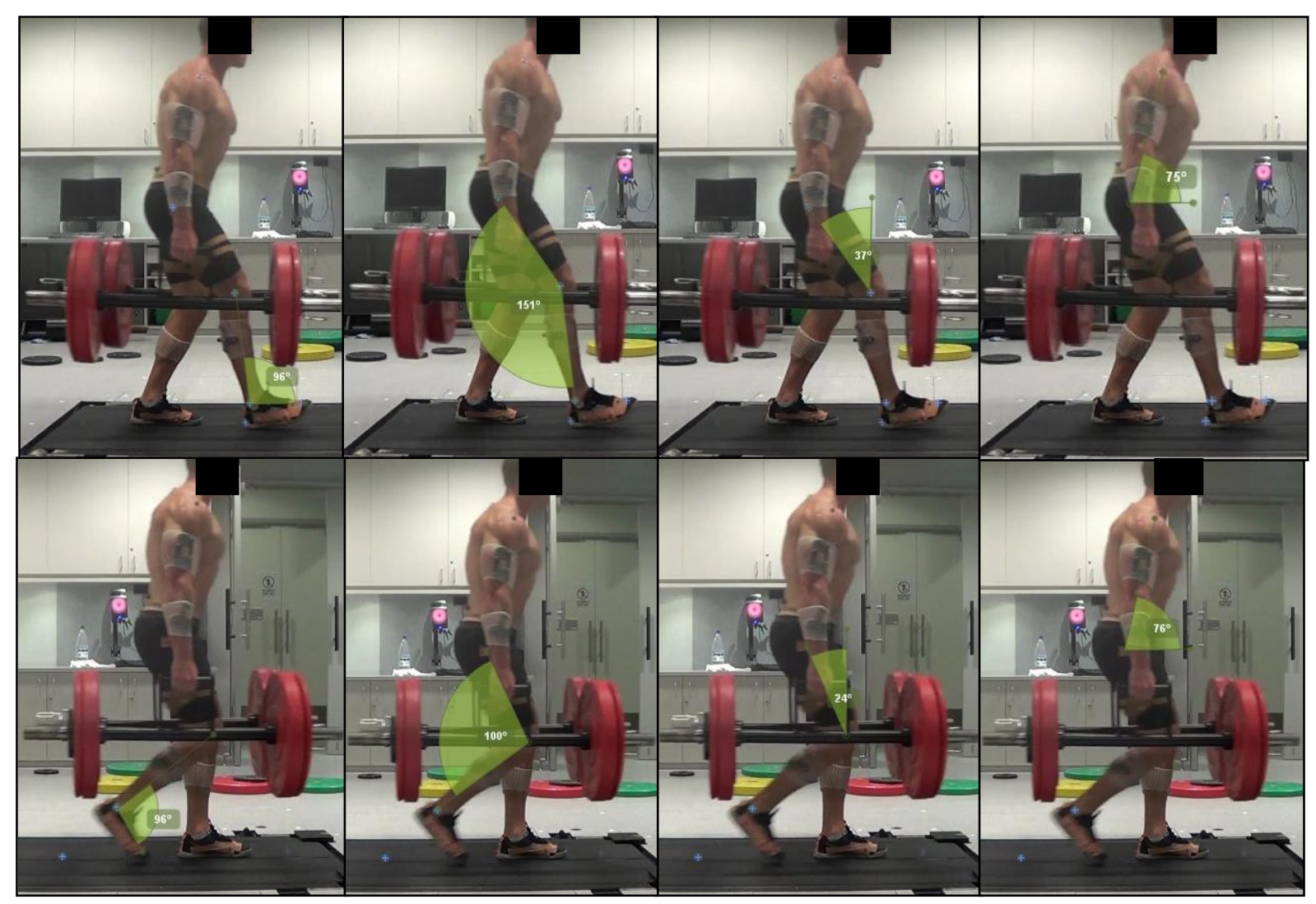

Figure 2: Pictorial Representation of the Four Angles Measured in the 2D Analysis of Farmers Walk. The Top Row From Left to Right Depicts the Ankle, Knee, Hip and Trunk Angles at Foot Strike and the Bottom Row at Toe Off 
Biomechanical Analysis of the Farmers Walk

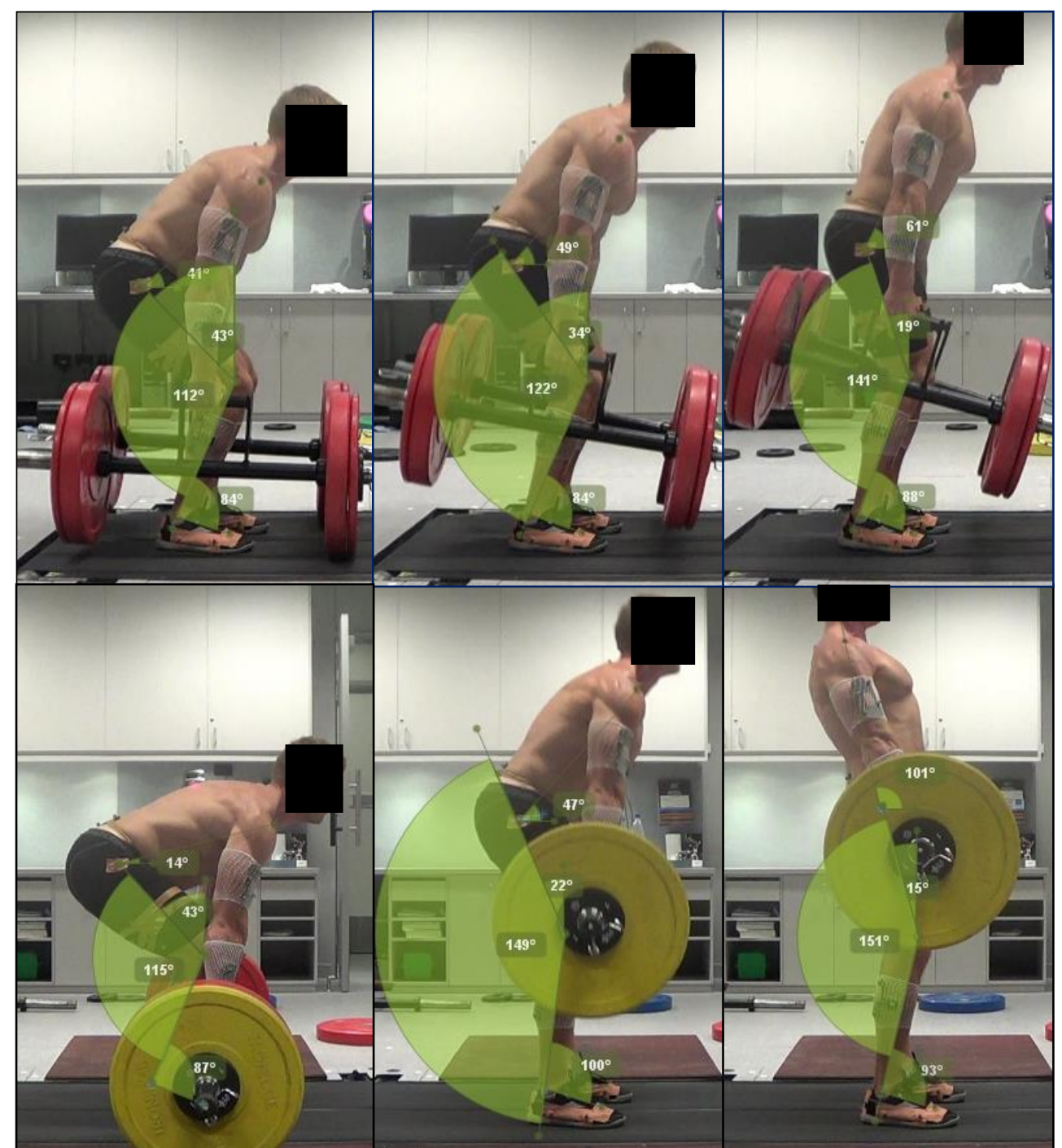

Figure 3: Pictorial Representation of the Four Angles Measured at LO, KP and LC (From Left to Right) in the Farmers Lift (top row) and Deadlift (bottom row) 

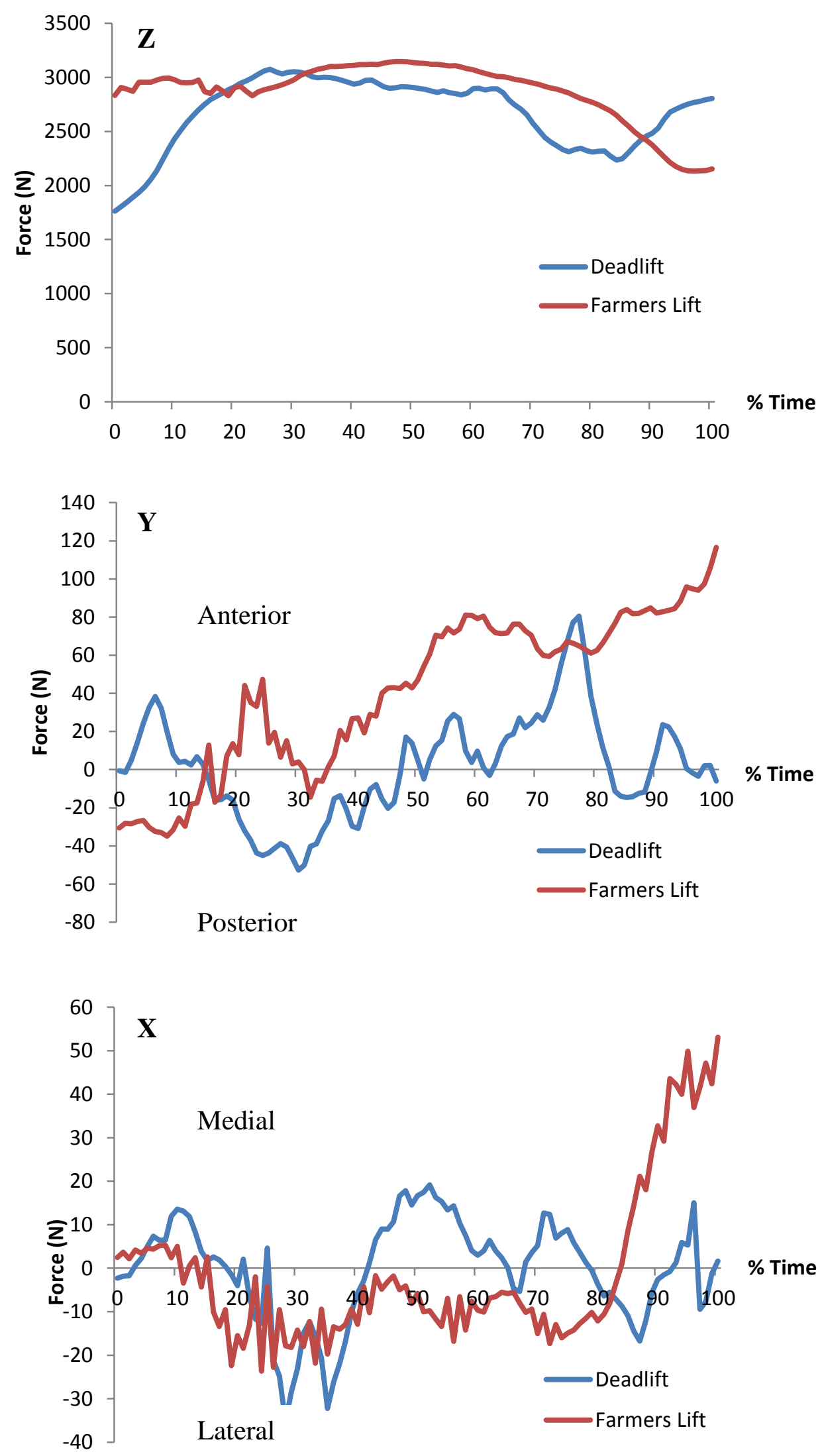

Figure 4: Group Mean Vertical (top), Anterior/Posterior (middle) and Medial/Lateral (bottom) Force-Time Curves (Normalised to Percentage of Mean Lift Time) Obtained With a $70 \%$ 1RM Load 
Biomechanical Analysis of the Farmers Walk

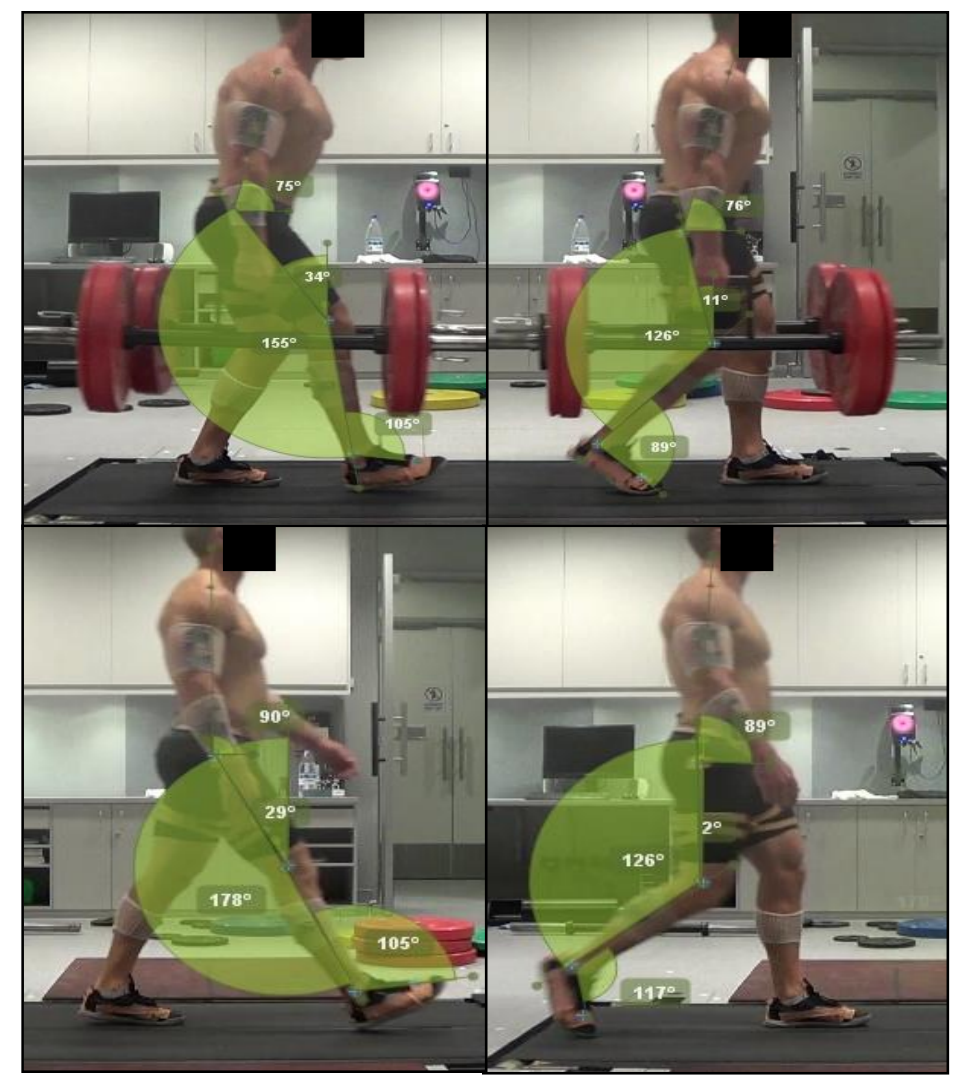

Figure 5: Pictorial Representation of Differences Between the Farmers Walk and Unloaded Walk at Heel Strike (left) and Toe Off (right) at 3-4 m 

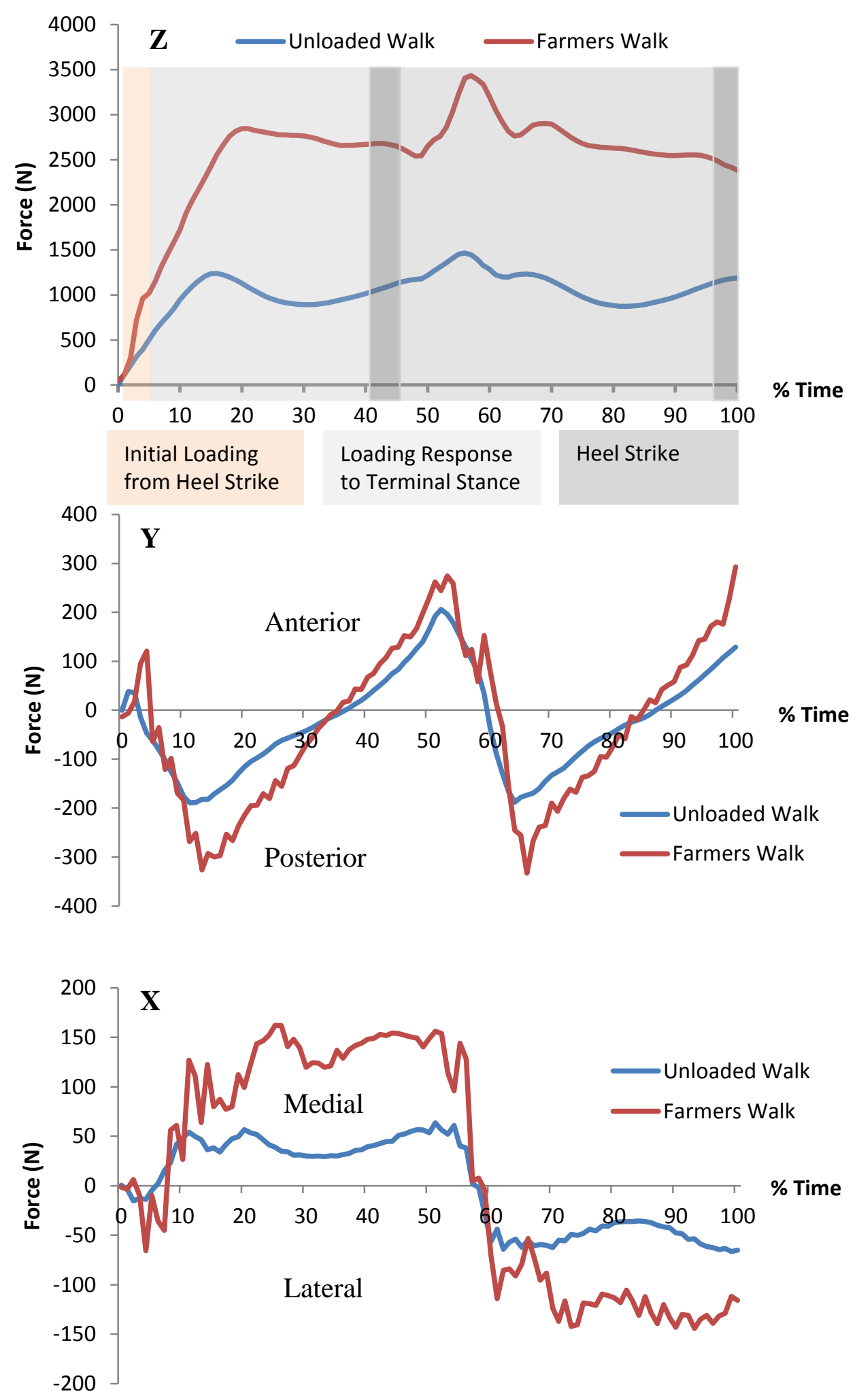

Figure 6: Group Mean Vertical (Top), Anterior/Posterior (Middle) and Medial/Lateral (Bottom) Average Vertical Force-Time Curves (Normalised to Percentage of Mean Lift Time) Obtained with Unloaded Walk at $3-4 \mathrm{~m}$ and the Farmers Walk With 70\% 1Repetition Maximum Load at 3 - 4 m. Graphs Depict Loading Response From Heel Strike to Heel Strike for One Stride (i.e. Two Steps) 
Biomechanical Analysis of the Farmers Walk 